\title{
NGHIÊN CÚU THỰC NGHIỆM SÂYY KHỔ QUA CẮT LÁT TRÊN TỦ SẤY SỬ DỤNG ĐÈN HALOGEN
}

\author{
TRÀ̀ ĐÌNH ANH TUẤN \\ Khoa Công nghệ Nhiệt lạnh, Trương Đại học Công nghiệp Thành phố Hồ Chí Minh; \\ trandinhanhtuan@iuh.edu.vn
}

Tóm tắt. Trong nghiên cứu này đã tiến hành thực nghiệm xác định chế độ sấy phù hợp cho Khổ Qua dạng lát, với công nghệ sấy đèn halogen. Thực nghiệm đã tiến hành khảo sát sự ảnh hường khác nhau của chế

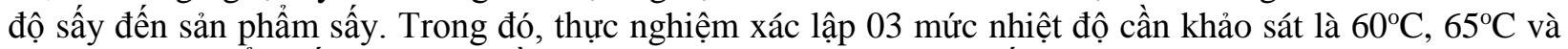
$70^{\circ} \mathrm{C}$ với sản phẩm sấy có độ dày lần lượt là $3 \mathrm{~mm}, 5 \mathrm{~mm}$ và $7 \mathrm{~mm}$. Kết quả thực nghiệm được đánh giá qua hai yếu tố đó là độ ẩm sản phẩm sấy và màu sắc cảm quan. Kết quả, nghiên cứu đã xác định với Khổ Qua dày $5 \mathrm{~mm}$, nhiệt độ sấy $65^{\circ} \mathrm{C}$ trong thời gian sấy 9 giờ cho sản phẩm đạt độ ẩm $29.12 \%$ phù hợp với độ ẩm yêu cầu bảo quản và có màu sắc xanh tự nhiên và đẹp hơn khi so với sản phẩm hiện có mặt trên thị trường. Từ khóa. Độ ẩm sản phẩm sấy, Halogen, Khổ qua cắt lát, Nhiệt độ sấy, Thời gian sấy

\section{EXPERIMENTAL RESEARCH FOR BITTER GOURD BASED ON HALOGEN LAMP}

\begin{abstract}
In this study, we have conducted experiments to determine the suitable drying regime for Bitter gourd slice by employing halogen lamp technology. The experiment has investigated the effect of various parameters drying performance on the drying products. In which, the experiment established 03 temperature levels to be surveyed as $60^{\circ} \mathrm{C}, 65^{\circ} \mathrm{C}$ and $70^{\circ} \mathrm{C}$ with the drying products with thickness of $3 \mathrm{~mm}$, $5 \mathrm{~mm}$ and $7 \mathrm{~mm}$ respectively. Experimental results are assessed through two factors that are the drying product moisture content and the sensory color. As a result, research has determined that with the thickness of $5 \mathrm{~mm}$, the drying temperature of $65^{\circ} \mathrm{C}$ during the 9-hour drying time for the product to reach the moisture content of $29.12 \%$, consistent with the required humidity for preservation and with natural green color and beautiful than when compared to products currently on the market.
\end{abstract}

Keywords. Bitter gourd slice, Drying Temperature, Drying time, Halogen, Moisture content

\section{TỔNG QUAN}

Kỹ thuật sấy là một trong những kỹ thuật rất lâu đời và là một sự kết hợp từ nhiều lĩnh vực khác nhau như khoa học, công nghệ, nền tảng kiến thức thực tiễn (đúc kết từ quan sát thực nghiệm và yếu tố kinh nghiệm của nhân viên kỹ thuật vận hành). Cho đến hiện nay, sấy là lĩnh vực được ứng dụng rất rộng rãi trong rất nhiều lĩnh vực khác nhau như nông nghiệp[1], sản xuất gốm sứ[2], hóa học[3], công nghệ dược phẩm[4], giấy, dệt may và đặc biệt trong lĩnh vực thực phẩm[5]. Khi một quá trình sấy xảy ra, dưới tác động của các yếu tố môi trường bên ngoài như nhiệt độ, độ ẩm, vận tốc, cũng như là tính chất, cấu trúc vật lý của bản thân vật liệu sấy, khi đó bên trong vật liệu sấy xuất hiện một cách đồng thời quá trình chuyển khối - nhiệt. Từ đó có thể dễ dàng thấy rằng, sấy là một lĩnh vực có kỹ thuật phức tạp bởi vì cho đến hiện nay vẫn chưa có một phương trình toán học nào có thể mô tả đầy đủ các mối liên quan giữa quá trình chuyển khối-nhiệt xảy ra bên trong vật liệu và các yếu tố ảnh hưởng đến quá trình sấy như trình bày ở trên. Chính vì vậy, trong nhiều thập kỷ qua, sấy vẫn luôn là lĩnh vực thôi thúc các nhà khoa học quan tâm và tiếp tục nghiên cứu để hoàn thiện hơn nữa các quá trình sấy, chế độ sấy.

Hiện nay có rất nhiều loại hệ thống sấy được phát triển và ứng dụng vào công nghiệp sản xuất. Mỗi một loại hệ thống sấy đều tồn tại ưu nhược điểm. Nhìn chung, hệ thống sấy có thể được phân loại, một cách tương đối, thành hai loại hệ thống sấy đó là hệ thống sấy sử dụng nguồn năng lượng tự nhiên và hệ thống sấy sử dụng nguồn năng lượng nhân tạo. Đối với hệ thống sấy sử dụng nguồn năng lượng tự nhiên có thể kể đến hệ thống sấy sử dụng nguồn năng lượng mặt trời, nguồn năng lượng địa nhiệt, nguồn năng lượng gió[6]. Nhìn chung, hệ thống sấy sử dụng nguồn năng lượng tự nhiên có ưu điểm tận dụng được nguồn năng lượng sẵn có, giúp tiết kiệm được năng lượng. Tuy nhiên, hệ thống này lại có nhược điểm rất lớn đó là thiếu chủ động và khả năng kiểm soát được các thông số trong quá trình sấy. Do vậy, với hệ thống sấy sử dụng năng lượng tự nhiên sẽ khó áp ứng được yêu cầu tạo ra các sản phẩm sấy có chất lượng cao trong 
hệ thống công nghiệp. Để khắc phục nhược điểm của hệ thống sấy tự nhiên, vì vậy, việc nhiên cứu và phát triển hệ thống sấy sử dụng năng lượng nhân tạo là cần thiết. Đối với hệ thống sấy sử dụng năng lượng nhân tạo, hiện nay được phát triển rất mạnh mẽ và đa dạng chủng loại như sấy đối lưu, sấy bức xạ[7], sấy bằng các dạng sóng, sấy bằng từ trường... Có thể kể đến các loại hệ thống sấy được sử dụng phổ biến hiện nay như hệ thống sấy bằng tần số vô tuyến (Radio-Frequency) được ứng dụng trong chế biến thực phẩm đã được công bố bởi nhóm tác giả Bo và cộng sự [8]. Nhóm tác giả Hebbar [9] đã nghiên cứu chế độ sấy trên hệ thống sấy kết hợp hồng ngoại và không khí nóng để sấy các khoai tây và carrot. Ngoài các loại hệ thống sấy được trình bày trên, công nghệ sấy sử dụng đèn halogen cũng được phát triển khá mạnh mẽ, bởi tính đơn giản và hiệu quả trong việc kiểm soát nhiệt độ sấy - là một trong những yếu tố đóng vai trò rất quan trọng của chế độ sấy. Gulum Sumnu và cộng sự đã nghiên cứu ứng dụng kết hợp halogen và sóng microwave để sấy carrot. Kết quả cho thấy, hệ thống sấy được đề xuất này cho sản phẩm carrot có chất lượng cao hơn và thời gian sấy ngắn hơn khi so với hệ thống sấy gia nhiệt bằng không khí nóng thông thường[10]. Chính vì vậy, trong bài nghiên cứu này tiếp tục đề xuất sử dụng halogen để thực hiện tìm chế độ sấy phù hợp. Trong lĩnh vực sấy, khi nghiên cứu xác định chế độ sấy không thể thiếu vật liệu sấy. Trong bài nghiên cứu này Khổ Qua được chọn là đối tượng nghiên cứu. Khổ Qua là giống cây sinh trưởng thuộc khu vực nhiệt đới và cận nhiệt đới. Ngoài Việt Nam, Khổ Qua được trồng rất phổ biến ở Ân Độ, Trung Quốc, Caribbean. Khổ Qua từ xưa đã được con người chọn làm nguồn thực phẩm thiết yếu bởi lẽ nó chứa nhiều chất dinh dưỡng tốt cho sức khoẻ lại dễ chế biến, dễ trồng, dễ chăm sóc. Ngoài việc là một món ăn bổ dưỡng được sử dụng, nó còn là một vị thuốc với rất nhiều công dụng chữa bệnh. Có rất nhiều bài báo nghiên cứu đã công bổ cho thấy rằng Khổ Qua đem đến những lợi ích về y học như giúp cải thiện tiêu hóa và giảm mức đường huyết cho con người. Thành phần trong Khổ Qua rất ít calo và chất béo nhưng đầy đủ các chất dinh dưỡng quý giá như magiê, kẽm, phốt pho, sắt, betacaroten, canxi, kali,...[11]. Nó làm giảm tỷ lệ mắc các khuyết tật ống thần kinh ở trẻ sơ sinh, nguy cơ mắc các bệnh tim mạch [12], cũng làm giảm một số loại ung thư như thực quản, tuyến tụy và ung thư phổi[13]. Ngoài ra, tại Việt Nam, Khổ Qua từ lâu đã được dùng làm thuốc và như một cây thuốc, nó đã được sử dụng để điều trị các bệnh khác nhau như bệnh đái tháo đường, ho, bệnh đường hô hấp, bệnh ngoài $\mathrm{da}$, vết thương. Nó giúp làm sạch gan và tái tạo tế bào gan và giảm cân. Vì những lợi ích dinh dưỡng và công dụng tuyệt vời nêu trên nên nhu cầu sử dụng sản phẩm Khổ Qua dạng sấy khô ngày một tăng cao. Sản phẩm Khổ Qua dạng sấy khô được sử dụng như một loại trà thảo dược. Do vậy, việc nghiên cứu để tìm chế độ sấy phù hợp cho sản phẩm Khổ Qua sấy khô nhằm tạo ra những sản phẩm ngày càng chất lượng cao hơn, có thời gian bảo quản được lâu hơn là việc cần thiết.

Theo đề cập trên, trong lĩnh vực khoa học thực phẩm, sấy đóng vai trò rất quan trọng trong việc bảo quản. Với việc loại bỏ ẩm ra khỏi thực phẩm thông qua quá trình sấy sẽ ngăn cản sự phát triển và sinh sản của vi sinh vật, từ đó sẽ làm chậm các phản ứng gây suy giảm chất lượng sản phẩm thực phẩm. Tuy vậy, chất lượng của sản phẩm sấy cũng chịu ảnh hưởng lớn bởi điều kiện sấy cũng như phương pháp sây. Chẳng hạn như, nếu nhiệt độ sấy quá cao trong quá trình sấy thực phẩm dẫn đến một số phản ứng hóa học kèm theo một số thay đổi về cấu trúc, tính chất vật lý và cơ học của vật liệu sấy. Chúng bao gồm sự suy giảm màu sắc, hình thành lớp vỏ cứng bên ngoài, giảm chất lượng cảm quan, mất hoặc biến tính chất dinh dưỡng và mùi vị cũng như thay đổi hình dạng và kết cấu của đối tượng sấy[14]. Do vậy, ngoài các yếu tố sấy chủ yếu như vận tốc tác nhân sấy, độ ẩm thì việc xác định nhiệt độ sấy phù hợp cực kỳ quan trọng. Có rất nhiều nghiên cứu đã cho thấy rằng, đối với Khổ Qua, giá trị nhiệt độ sấy trong khoảng từ $40^{\circ} \mathrm{C}$ đến $80^{\circ} \mathrm{C}$, tùy theo bề dày của Khổ Qua và phương pháp sấy[11][15]. Xuất phát từ những tham khảo ban đầu đó, trong nghiên cứu này đề xuất nghiên cứu sấy Khổ Qua với các giá trị nhiệt độ từ $60^{\circ} \mathrm{C}-70^{\circ} \mathrm{C}$ với phương pháp sấy bằng đèn halogen.

Với những phân tích trên, trong bài báo này tiến hành nghiên cứu khảo sát quá trình sấy cho Khổ Qua với phương pháp gia nhiệt bằng công nghệ halogen với các mục tiêu nhằm xác định chế độ sấy phù hợp hơn, tạo ra được sản phẩm có chất lượng cao bởi vì các lí do sau:

i/ Mặc dù công nghệ đèn halogen có nhiều ưu điểm và đã được sử dụng rất rộng rãi trong lĩnh vực sấy, nhưng việc ứng dụng halogen cho sấy Khổ Qua chưa được nghiên cứu nhiều và đầy đủ hơn.

ii/Nới những công dụng của Khổ Qua được phân tích ở trên, vì vậy Khổ Qua cắt lát được chọn là đối tượng trong nghiên cứu này. 


\section{DŨ' LIẾU VÀ THỤ’C NGHIỆM}

\subsection{Mô hình thực nghiệm}

Nghiên cứu này thực hiện trên mô hình sấy như Hình 1, trong đó Hình 1(a) mô tả mô hình được thiết kế và sau khi hoành thành chế tạo. Mô hình sấy có kích thước dài x rộng x cao là 550x550x850 (mm), gồm có 2 tầng có 04 khay inox để chứa vật liệu sấy. Mỗi tầng bố trí 3 đèn halogen có công suất $100 \mathrm{~W} / 1$ bóng, nên vậy công suất tối đa của halogen sử dụng trong mô hình sấy là $600 \mathrm{~W}$, nhiệt độ tối đa trong buồng sấy là $90^{\circ} \mathrm{C}$. Các khay inox được đặt trên một trục xoay tròn, được điều chỉnh tốc độ xoay thông qua thiết bị biến tần. Nhiệt độ sấy sẽ được kiểm soát bởi thiết bị SSR được thiết lập với biên độ dao động là nhiệt độ cài đặt $\pm 2^{\circ} \mathrm{C}$. Khi nhiệt độ đạt giá trị cài đặt, thiết bị SSR sẽ điều chỉnh cường độ sáng của bóng đèn halogen để giảm nhiệt độ phát. Trong mô hình sấy bố trí 04 cảm biến nhiệt độ với sai số thiết bị đo là $\pm 0.02^{\circ} \mathrm{C}$ tại các vị trí bên ngoài để nhận thông tin nhiệt độ trước buồng sấy, có hai cảm biến nhiệt độ đặt trên mỗi ngăn để nhận thông tin nhiệt độ sấy và 01 cảm biển nhiệt độ đặt tại cửa hút ra ngoài để theo dõi thông tin nhiệt độ sau quá trình sấy. Lượng ẩm tách ra được đưa ra ngoài tại cửa hút được bố trí trên nóc tủ sấy.

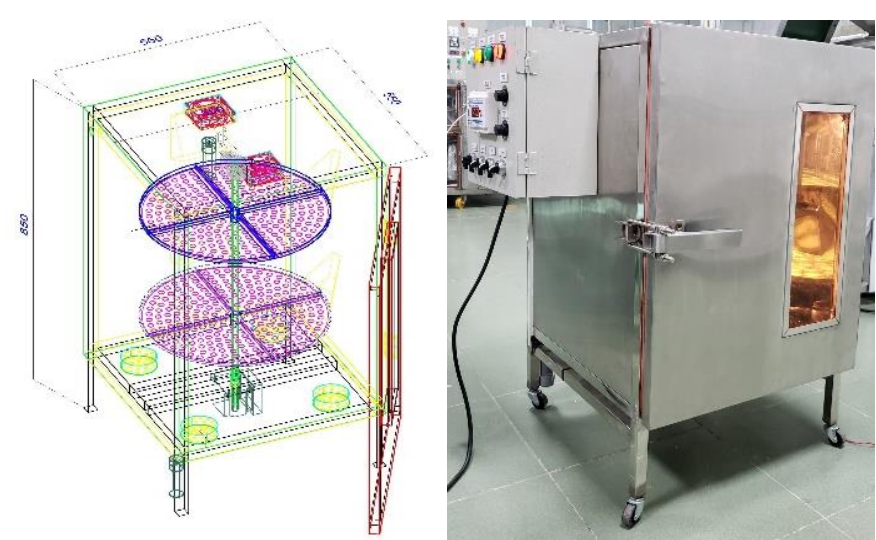

(a)

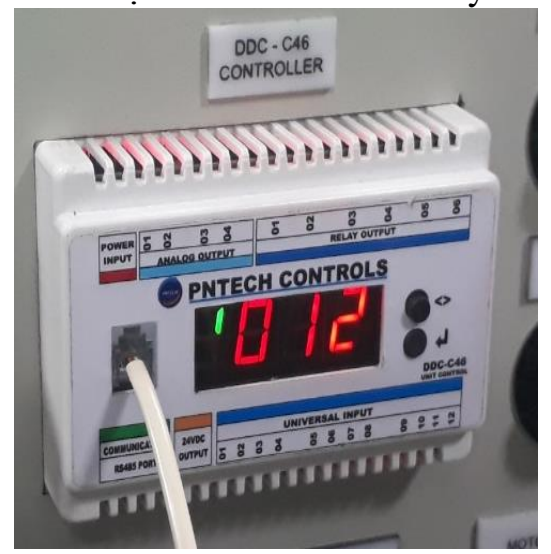

(b)

Hình 1: Mô hình sấy halogen - (a) Tủ sấy; (b) Thiết bị DDC-C46

Song song với thiết bị mô hình thí nghiệm, việc thu thập dữ liệu trong thí nghiệm được sử dụng thông qua thiết bị DDC-C46 (Hình 1b) giao tiếp với máy tính qua cổng RS32. Phần mềm điều khiển thiết bị DDC có giao diện như Hình 2. Do quá trình sấy là quá trình có sự thay đổi các yếu tố sấy rất lớn, để tăng độ tin cậy của dữ liệu, đòi hỏi dữ liệu thu thập được khi hệ thống đạt trạng thái ổn định. Do vậy, trong thí nghiệm của nghiên cứu này, số liệu sẽ được ghi lại từ phần mềm với khoảng thời gian là 2 phút/1lần.

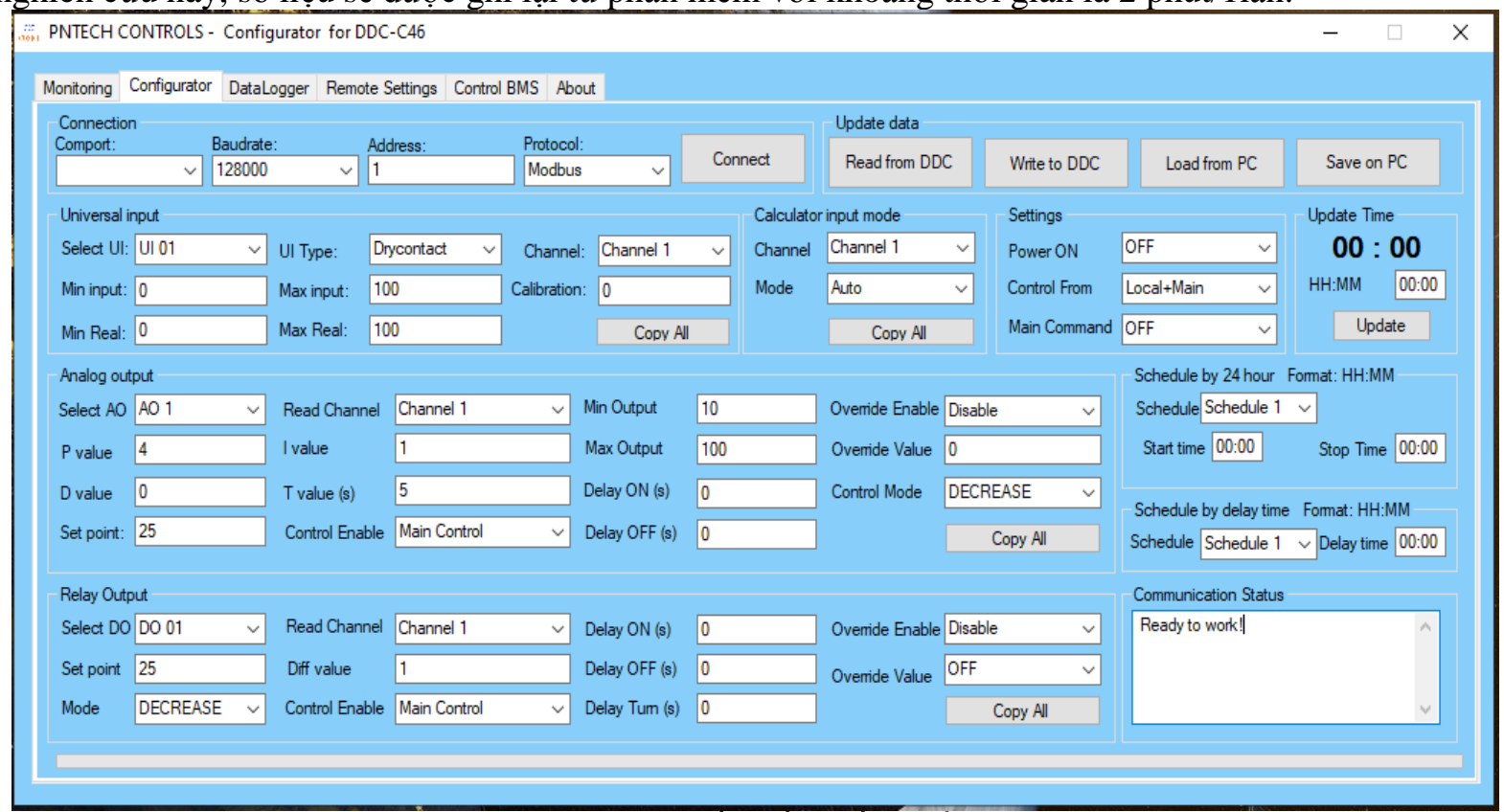

Hình 2: Giao diện phần mềm điều khiển DDC-C46 


\subsection{Bố trí thí nghiệm}

Trong nghiên cứu này sẽ tiến hành khảo sát các yếu tố tác động đến vật liệu sấy trong quá trình sấy đó là nhiệt độ, độ dày của sản phẩm. Với nhiệt độ, nghiên cứu này tiến hành thiết lập 03 mức nhiệt độ lần lượt là $60^{\circ} \mathrm{C}, 65^{\circ} \mathrm{C}, 70^{\circ} \mathrm{C}$. Vật liệu sấy là Khổ Qua dạng lát với độ dày khi tiến hành khảo sát thực nghiệm là $3 \mathrm{~cm}$, $5 \mathrm{~cm}, 7 \mathrm{~cm}$. Do đó, trong nghiên cứu này sẽ tiến hành khảo sát các ảnh hưởng đến quá trình sấy như sau:

- Ảnh hưởng của độ dày vật liệu sấy

- Ảnh hưởng của nhiệt độ sấy

- Ảnh hưởng của thời gian sấy

Trong quá trình thực hiện sấy, theo [16] và [17] công thức toán học nhằm xác định sự thay đổi độ ẩm của vật liệu sấy được tiến hành xác định theo định kỳ thời gian 10 phút/lần như sau :

Trong đó,

$$
\omega_{c}=\frac{m_{C}-m_{K}}{m_{C}}(1)
$$

$\omega_{c}$ : hàm lượng ẩm của vật liệu sấy tại thời điểm xác định $(\%)$

$\mathrm{m}_{\mathrm{c}}$ : khối lượng vật liệu sấy tại thời điểm $\mathrm{t},(\mathrm{g})$

$\mathrm{m}_{\mathrm{k}}$ : khối lượng vật liệu sấy tại thời điểm xác định $\mathrm{t}+1,(\mathrm{~g})$

\section{KẾT QUẢ VÀ THẢO LUẬN}

\subsection{Xác định độ ẩm ban đầu của vật liệu sấy}

Vật liệu sấy Khổ Qua là sản phẩm tươi, được mua tại chợ Gò Vấp mỗi buổi sáng. Trước khi tiến hành thực nghiệm, vật liệu sấy được rửa sạch, để khô trong môi trường tự nhiên, sau đó xác định hàm lượng ẩm ban đầu bằng phương pháp sấy kiệt để loại bỏ hoàn toàn ẩm trong tủ sấy $250^{\circ} \mathrm{C}$. Kết quả xác định được, nhìn chung Khổ Qua có hàm lượng ẩm khoảng từ $92 \%-95 \%$, và kết quả khá tương đồng so với các nghiên cứu đã công bố [11][17].

\subsection{Sấy thăm dò nhằm xác định thời gian sấy trong thực nghiệm}

Phương pháp thí nghiệm là sử dụng sản phẩm khổ qua có độ dày $5 \mathrm{~mm}$, nhiệt độ sấy được chọn thiết lập là $70^{\circ} \mathrm{C}$. Các khoảng thời gian sấy khảo sát lần lượt 6 giờ , 7 giờ, và 8 giờ. Kết quả được trình bày hình sau:

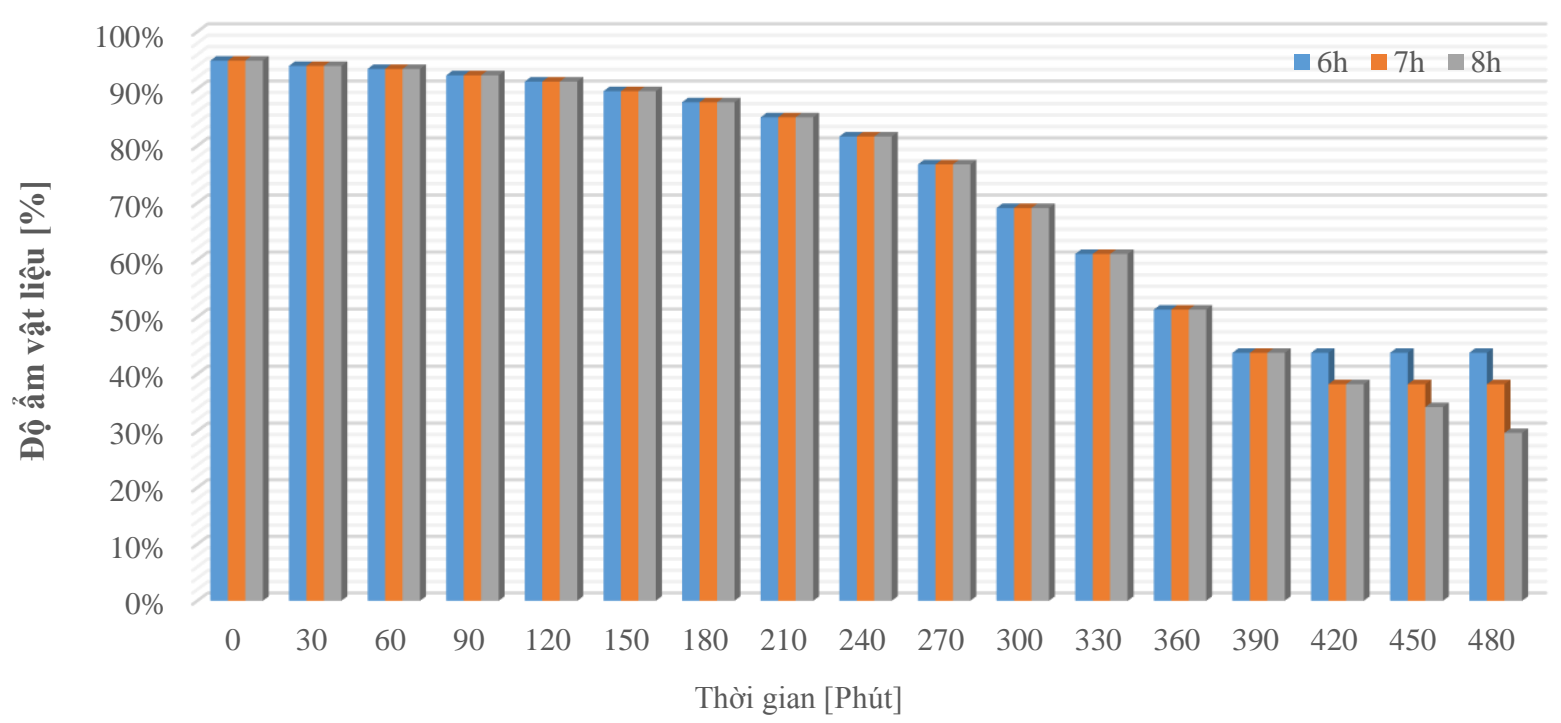

Hình 3: Ảnh hưởng thời gian sấy đến độ ẩm vật liệu sấy

Qua kết quả khảo sát, nếu thực hiện sấy với thời gian sấy là 6 giờ thì độ ẩm vật liệu sấy là $43.73 \%, 7$ giờ thì độ ẩm vật liệu sấy là $38.24 \%$ và 8 giờ thì độ ẩm vật liệu sấy là $29.67 \%$. Cùng với đó, trong nghiên cứu này cũng đã tiến hành tham khảo độ ẩm của các sản phẩm sấy hiện có mặt trên thị trường, kết quả nhìn chung có độ ẩm khoảng $30 \%$. Như vậy, để đạt độ ẩm bảo quản cuối cùng của sản phẩm Khổ Qua sấy, cần thực hiện khoảng thời gian sấy khoảng 8 giờ với nhiệt độ sấy $70^{\circ} \mathrm{C}$. Do đó, trong nghiên cứu này, đã chọn thời gian sấy là 8 giờ là khoảng thời gian chung cho tất cả các nghiên cứu khảo sát.

\subsection{Xác định ảnh hưởng của độ dày vật liệu sấy đến quá trình sấy}

Như trình bày trên, trong nghiên cứu này lần lượt thực hiện tiến hành thí nghiệm ở 03 mức độ dày khác nhau của vật liệu sây lần lượt là $3 \mathrm{~mm}, 5 \mathrm{~mm}, 7 \mathrm{~mm}$, với một giá trị nhiệt độ cố định trong cùng một khoảng 
thời gian sấy là như nhau. Trong trường hợp này, nghiên cứu này đã chọn nhiệt độ thí nghiệm là $65^{\circ} \mathrm{C}$ trong thời gian $8 \mathrm{~g}$. Kết quả được thể hiện trên Hình 3 như sau:

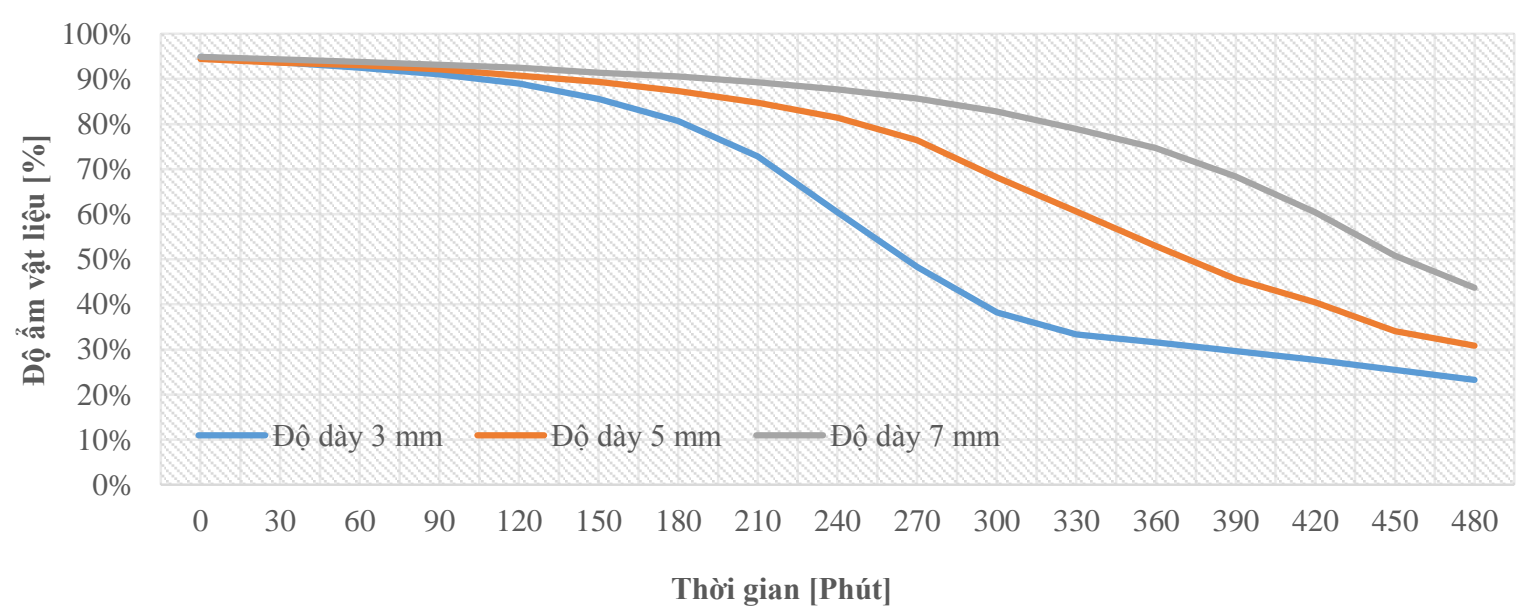

Hình 4: Đường cong sấy của Khổ Qua với độ dày khác nhau ở nhiệt độ sấy $65^{\circ} \mathrm{C}$

Hình 4 thể hiện sự thay đổi hàm lượng ẩm của Khổ Qua với 03 loại độ dày khác nhau trong quá trình sấy ở nhiệt độ sấy là $65^{\circ} \mathrm{C}$. Qua Hình 4 dễ nhận thấy rằng, trong khoảng thời gian 100 phút đầu, tốc độ sấy của cả 3 loại VLS không có nhiều khác biệt. Điều này có thể được lý giải, nhiệt cung cấp trong giai đoan này chủ yếu để gia nhiệt tách hàm lượng ẩm tự do ở bề mặt ngoài của VLS. Hàm lượng ẩm tự do bề mặt ngoài này chiếm tỷ trọng không đáng kể trong tổng hàm lượng ẩm của VLS. Giai đoạn 2, từ phút 130 đến 360 , chúng ta dễ dàng nhận thấy có sự khác biệt rất lớn về tốc độ sấy của 3 loại VLS này. Rõ ràng, với VLS có độ dày $3 \mathrm{~mm}$ có tốc độ sấy là nhanh nhất, VLS có độ dày $7 \mathrm{~mm}$ có tốc độ sấy chậm nhất. Kết quả, độ ẩm của vật liệu sấy sau khi kết thúc quá trình sấy lần lượt là $23.33 \%$ đối với Khổ Qua dày $3 \mathrm{~mm}, 30.41 \%$ đối với Khổ Qua dày $5 \mathrm{~mm}$ và $45.08 \%$ đối với Khổ Qua dày $7 \mathrm{~mm}$. Ngoài ra, khi tiến hành so sánh màu sắc của các sản phẩm sau khi kết thúc quá trình sấy (Hình 5). Kết quả so sánh có thể thấy rằng sản phẩm có độ dày $7 \mathrm{~mm}$ là ít biến đổi màu nhất, còn sản phẩm dày $3 \mathrm{~mm}$ có hiện tượng bắt đầu ngả vàng, màu sắc kém tươi. Tuy nhiên độ ẩm của sản phẩm $7 \mathrm{~mm}$ với độ ẩm khi kết thúc quá trình sấy này là $45.08 \%$ là quá cao chưa đạt độ ẩm của yêu cầu bảo quản. Trong khi đó, với sản phẩm Khổ Qua dày $5 \mathrm{~mm}$, có màu sắc sau sấy vẫn sắc trẳng như sản phẩm tươi, đồng thời vẫn đáp ứng được độ ẩm bảo quản như các sản phẩm trên thị trường.

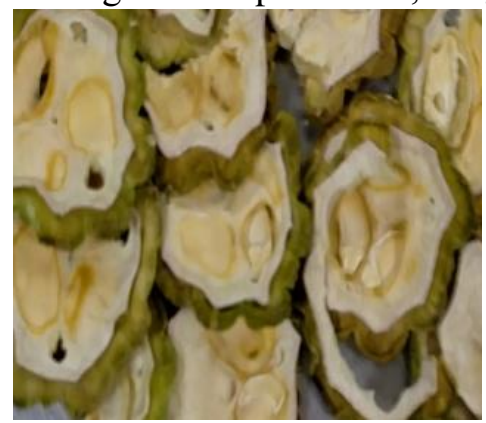

Dày $3 \mathrm{~cm}$

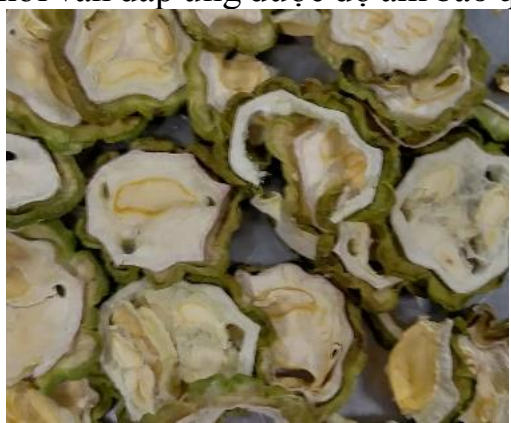

Dày $5 \mathrm{~cm}$

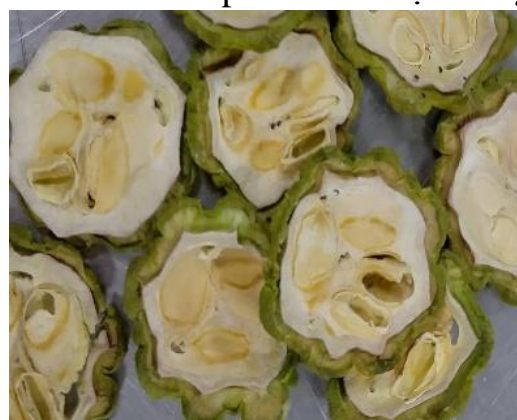

Dày $7 \mathrm{~cm}$

\subsection{Xác định ảnh hưởng của nhiệt độ sấy đến vật liệu sấy}

Hình 5: Kết quả sấy trên Khổ Qua dạng lát với độ dày khác nhau

Trong thí nghiệm này, nhóm tác giả tiến hành khảo sát ảnh hưởng của nhiệt độ sấy đến quá trình sấy và vật liệu sấy. Để khảo sát yếu tố ảnh hưởng này, trong nghiên cứu này đã chọn độ dày lát cắt khổ qua là $5 \mathrm{~mm}$ và nhiệt độ sấy được thiết lập lần lượt ở các mức $60^{\circ} \mathrm{C}, 65^{\circ} \mathrm{C}, 70^{\circ} \mathrm{C}$, trong thời gian sấy là 8 giờ. Kết quả được trình bày trên hình 5 như sau 


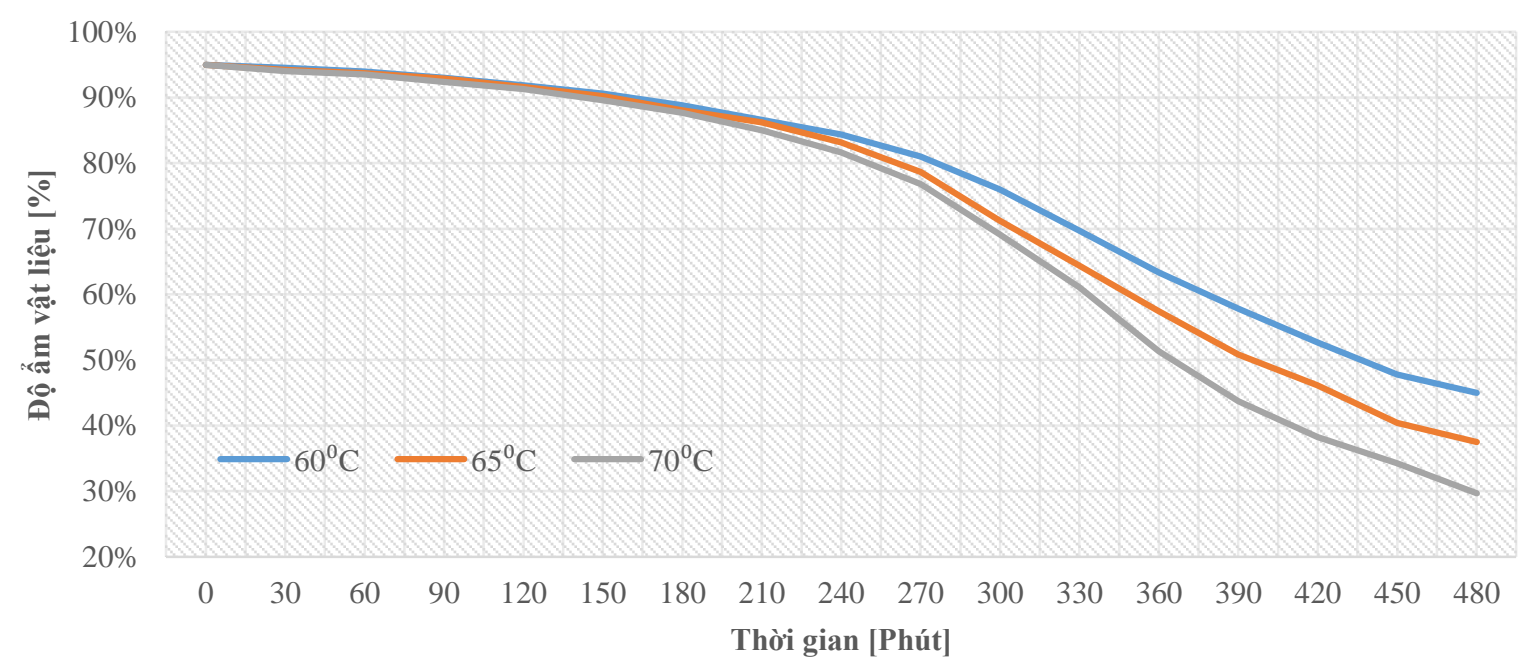

Hình 6: Đường cong sấy của Khổ Qua ở nhiệt độ sấy khác nhau

Qua Hình 6, có thể thấy rằng trong khoảng nửa thời gian đầu, tức đến 250 phút, dưới ảnh hưởng của nhiệt độ sấy, tốc độ giảm ẩm của tất cả các vật liệu sấy gần như nhau. Điều này có thể lý giải, hầu như nhiệt lượng cung cấp cho vật liệu sấy trong giai đoạn này chỉ có tác dụng với lượng ẩm bề mặt. Từ sau giai đoạn này, tốc độ sấy do ảnh hưởng bởi 03 chế độ nhiệt độ sấy mới co sự phân biệt rõ hơn. Và, tốc độ giảm ẩm của vật liệu sấy dưới tác dụng của nhiệt độ sấy $70^{\circ} \mathrm{C}$ là nhanh nhất. Khi kết thúc quá trình sấy, độ ẩm cuối cùng của vật liệu sấy lần lượt đạt là $45 \%$ khi nhiệt độ sấy là $60^{\circ} \mathrm{C}, 37.79 \%$ khi nhiệt độ sây là $65^{\circ} \mathrm{C}$ và $30.41 \%$ khi thực hiện sấy ở $70^{\circ} \mathrm{C}$ trong thời gian sấy là $8 \mathrm{~h}$. Ngoài ra, tương tự như trên, thực nghiệm cũng tiến hành so sánh màu sắc của vật liệu sấy sau khi kết thúc quá trình sấy thì sản phẩm sấy ở $60^{\circ} \mathrm{C}$ giữ được màu xanh tốt hơn so với sản phẩm sấy ở $65^{\circ} \mathrm{C}$ và $70^{\circ} \mathrm{C}(\mathrm{Hình} 7)$. Qua kết quả có thể thấy rằng, với độ dày $5 \mathrm{~mm}$ của vật liệu sấy, khi tiến hành sấy với thời gian 8 giờ, thì sản phẩm sau sấy với nhiệt độ $60^{\circ} \mathrm{C}$ chưa thể đạt yêu cầu, với nhiệt độ $65^{\circ} \mathrm{C}$ cùng với màu sắc gần như ở dạng tươi, sản phẩm gần xấp xỉ độ ẩm yêu cầu và cuối cùng với nhiệt độ $70^{\circ} \mathrm{C}$ độ ẩm sản phẩm đã đạt yêu cầu, nhưng màu sắc bắt đầu ngả vàng.

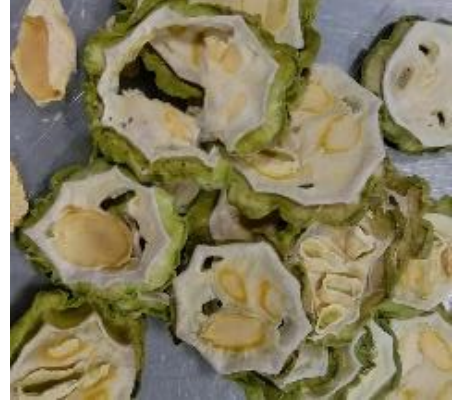

$\left(60^{\circ} \mathrm{C}\right)$

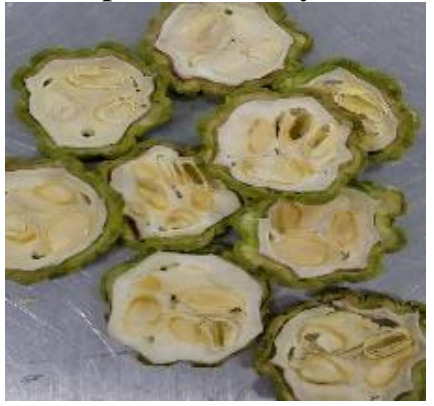

$\left(65^{\circ} \mathrm{C}\right)$

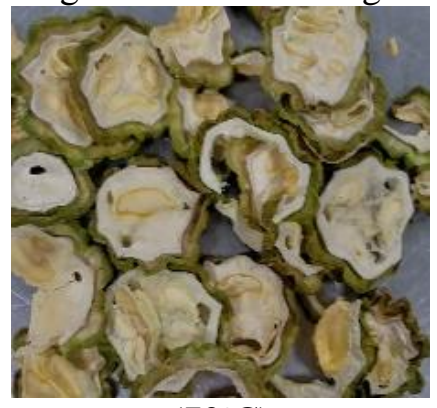

$\left(70^{\circ} \mathrm{C}\right)$

\subsection{So sánh với sản phẩm trên thị trường}

Qua các thực nghiệm trên, nhận thấy rẳng nếu thực hiện sấy ở nhiệt độ sấy $65^{\circ} \mathrm{C}$ cho sản phẩm Khổ Qua với độ dày $5 \mathrm{~mm}$, cho nhiều kết quả ưu điểm nhất. Vì vậy, nghiên cứu này thực hiện sấy lại với chế độ sấy này với thời gian sấy là 9 giờ, để sản phẩm đạt được độ ẩm yêu cầu trong bảo quản. Kết quả sẽ được so sánh với sản phẩm trên thị trường, cụ thể chọn sản phẩm trong siêu thị Emart. Kết quả được thể hiện qua Hình 8. Qua đó, dễ thấy rằng, sản phẩm của nghiên cứu có màu sắc tốt hơn, màu xanh của sản phẩm gần như còn tự nhiên, trong khi đó sản phẩm trên thị trường đã bị biến đổi sang đen. Về độ ẩm của sản phẩm khi tiến hành sấy ở chế độ này đã đạt được $29.12 \%$, như vậy đã đáp ứng được yêu cầu về độ ẩm bảo quản. 


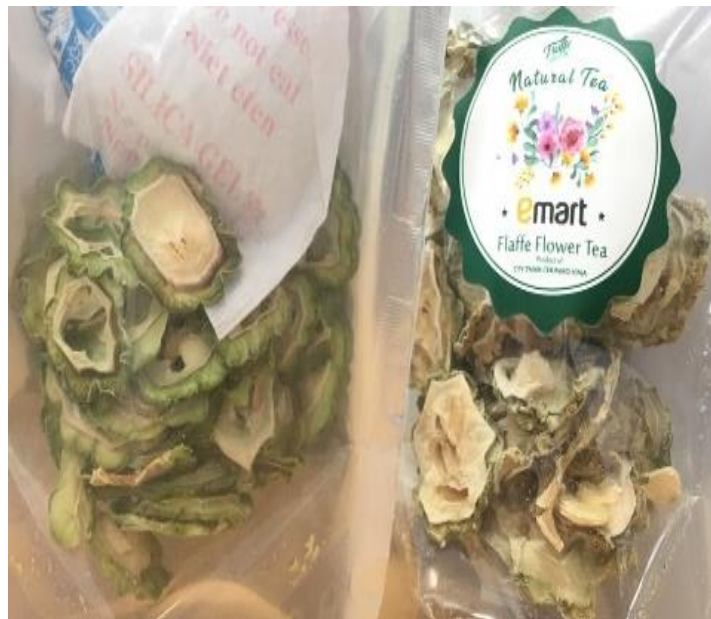

Hình 8: So sánh sản phẩm thực nghiệm với sản phẩm trên thị trường

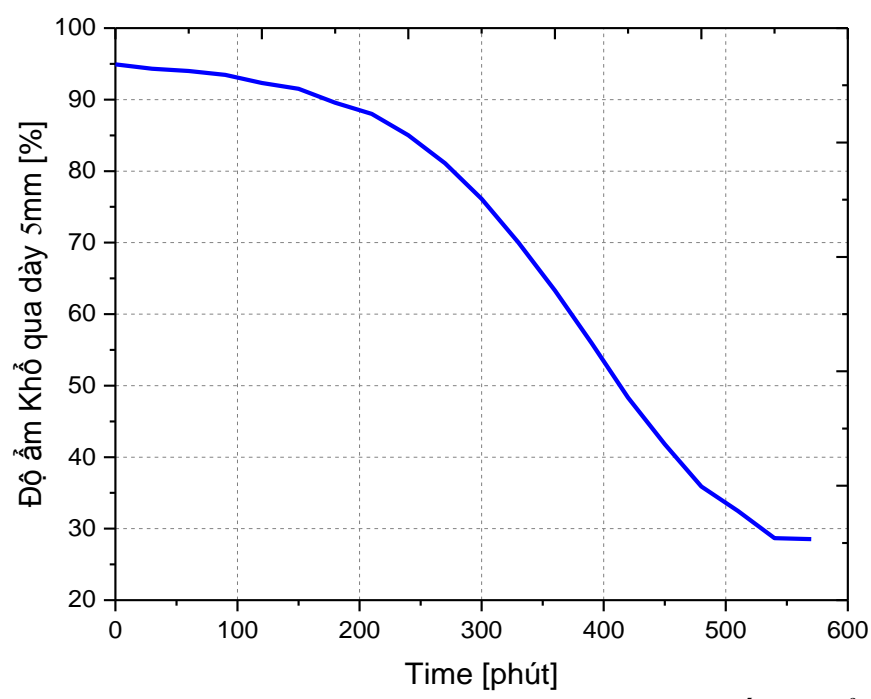

Hình 9: Đồ thị quan hệ giữa thời gian và vật liệu sấy (Khổ Qua) dày $5 \mathrm{~mm}$ trong $9 \mathrm{~h}$

\section{KẾT LUẬN}

Qua những kết thí nghiệm và hình ảnh sản phẩm thu được nêu trên. Ta nhận thấy rằng độ dày sản phẩm ảnh hưởng lớn nhất đến quá trình sấy khổ qua, độ dày càng lớn thì thời gian sấy càng lâu và ngược lại. Sau đó là nhiệt độ sấy, với nhiệt độ càng cao thì thời gian sấy càng giảm nhưng ảnh hưởng rất nhiều đến màu sắc của sản phẩm. Với đối tượng sấy là khổ qua và sử dụng đèn Halogen trong phạm vi nghiên cứu thực nghiệm này, thì sản phẩm có độ dày $5 \mathrm{~mm}$, sấy ở nhiệt độ $65^{\circ} \mathrm{C}$, trong 9 giờ với độ ẩm cuối là $29.12 \%$, còn lưu lại màu sắc xanh tự nhiên, đảm bảo chất lượng, phù hợp với điều kiện sử dụng và bảo quản trong thời gian dài.

\section{TÀI LIỆU THAM KHẢO}

[1] G.A. Çiftçioğlu, F. Kadırgan, M.A.N. Kadırgan, G. Kaynak, Smart agriculture through using cost-effective and high-efficiency solar drying, Heliyon. 6, 2020.

[2] T. V Vakalova, I.B. Revva, Use of zeolite rocks for ceramic bricks based on brick clays and clay loams with high drying sensitivity, Constr. Build. Mater. 255, 2020.

[3] S. Septien, S.W. Mirara, B.S.N. Makununika, A. Singh, J. Pocock, K. Velkushanova, C.A. Buckley, Effect of drying on the physical and chemical properties of faecal sludge for its reuse, J. Environ. Chem. Eng. 8, 2020.

[4] A.B. Meneguin, H. da Silva Barud, R.M. Sábio, P.Z. de Sousa, K.F. Manieri, L.A.P. de Freitas, G. Pacheco, J.D. Alonso, M. Chorilli, Spray-dried bacterial cellulose nanofibers: A new generation of pharmaceutical excipient intended for intestinal drug delivery, Carbohydr. Polym. 249, 2020.

[5] N. Ahmed, J. Singh, H. Chauhan, P.G.A. Anjum, H. Kour, Different Drying Methods : Their Applications and Recent Advances, Int. J. Food Nutr. Saf. 4, 34-42, 2013.

[6] O. Prakash, A. Kumar, Solar greenhouse drying : A review, 29, 905-910, 2014.

[7] M. Adonis, M.T.E. Khan, Combined convective and infrared drying model for food applications, IEEE Afri. Conf. 2, 1049-1052, 2004.

[8] B. Ling, J.G. Lyng, S. Wang, Radio-frequency treatment for stabilization of wheat germ: Dielectric properties and heating uniformity, Innov. Food Sci. Emerg. Technol. 48, 66-74, 2018.

[9] H.U. Hebbar, K.H. Vishwanathan, M.N. Ramesh, Development of combined infrared and hot air dryer for vegetables, J. Food Eng. 65 (2004) 557-563, 2004. 
[10] G.S. Ã, E. Turabi, M. Oztop, Drying of carrots in microwave and halogen lamp - microwave combination ovens, 38, 549-553, 2005.

[11] I. Biswas, S. Mandal, M. Samadder, S. Mukherjee, B. Chandra, K. Viswavidyalaya, W. Bengal, Drying characteristics of bitter gourd (Momordica charantia), 14, 111-116, 2018.

[12] J.P. Simon, E.S. Hudes, W.S. Brown, Serum ascorbic acid and cardiovascular disease prevalence in US adults, Epidemiology. 9, 316-21, 1988.

[13] M.J. Wargovich, Anticancer properties of fruits and vegetables, HortScience. 35, 573-575, 2000.

[14] I. Dincer, M.M. Hussain, B.S. Yilbas, A.Z. Sahin, Development of a new drying correlation for practical applications, Int. J. Energy Res. 26, 245-251, 2002.

[15] J.K. Yan, L.X. Wu, Z.R. Qiao, W.D. Cai, H. Ma, Effect of different drying methods on the product quality and bioactive polysaccharides of bitter gourd (Momordica charantia L.) slices, 2019.

[16] D.B. A, S. Das, R.S. Dhua, Dehydration for Better Quality Value Added Product of Bitter Gourd (Momordica charantia L.), Indian J. Pharm. Biol. Res. 4, 39-45, 2016.

[17] W. Jin, M. Zhang, W. Shi, Evaluation of ultrasound pretreatment and drying methods on selected quality attributes of bitter melon (Momordica charantia L. Dry. Technol. 37, 387-396, 2019.

Ngày nhận bài: 16/11/2020

Ngày chấp nhận đăng: 30/03/2021 